\title{
INFLUENCE OF WIND AND EARTHQUAKE ON A SINGLE MODIFICATION HIGH RISE STRUCTURE IN FOUR METRO CITIES OF INDIA
}

\author{
Reeti Sarkar ${ }^{1}$, Ranjit Patil ${ }^{2}$, Kalyana Rama J S ${ }^{\mathbf{3}}$ \\ ${ }^{1}$ Undergraduate Student, Department of Civil Engineering, BITS Pilani Hyderabad Campus, India \\ ${ }^{2}$ Undergraduate Student, Department of Civil Engineering, BITS Pilani Hyderabad Campus, India \\ ${ }^{3}$ Lecturer, Department of Civil Engineering, BITS Pilani Hyderabad Campus, India
}

\begin{abstract}
Natural disasters are increasingly a major cause for concern for the construction industry, due to the widespread damage to property. In India in particular, cases of wind (esp. cyclone) and earthquake damage have been escalating rapidly, which requires counter measures in terms of earthquake and wind resistant design of buildings. While the Indian Standards provide a method for calculation of wind and earthquake loads respectively, very little indigenous data exists in terms of research and analysis of design solutions in the field - particularly a design which can offer combined resistance to both forces. In the present study therefore, the four metro cities of India - Mumbai, Delhi, Kolkata and Chennai - are selected, and their geographical parameters (in terms of earthquake and wind) is studied. A residential high rise building with single modification in building shape is designed and tested in the conditions of each of these cities using computational tool. The results in terms of both wind and earthquake resistance are tested against a regular rectangular building, in order to decide the dominating loads and effect of alteration of designs in the Indian housing construction industry. The study extends to results on mode shapes and frequencies under seismic loading.
\end{abstract}

Keywords: Wind Loads, Earthquake, Aerodynamic Shape, Mode Shapes, Tall Buildings

\section{INTRODUCTION}

Instances of natural disasters like cyclones, hurricanes and earthquakes have been increasing in recent times owing to several possible reasons, ranging from global climatic upheavals to human activity. Indian buildings in particular, are ill equipped to combat the effect of sudden natural disasters. Hence, endeavors are necessary to determine simple design solutions: such that buildings may become robust and enduring towards such disasters, without too much added expense for construction.

The objective of the present study is to identify a suitable single modification to a square high rise, and model the structural skeleton of the building in STAAD for the two cases. Seismic and wind loads are applied to the two cases and it is determined whether the modification influences base shear or story drift in the building. The study adheres to calculation of loads according to IS 875 (Part 3) for wind load, and IS 1893:Part I for earthquake loads.

The prevailing conditions in four Indian cities: Chennai, Delhi, Kolkata and Mumbai, are used for the purposes of this study. As the major metropolitan cities of India, these cities experience the maximum impact of rise in population as well as housing projects, and are therefore suitable for this study.
The study of extensive literature was used primarily to investigate possible modifications to the square building under study.

\subsection{Aerodynamic Shape}

Several possible modifications exist for the aerodynamic shape of a building:

- the base polygonal shape of the building can be altered from square to circular, hexagonal, octagonal, etc.

- buildings may be tapered or have setbacks added

- corners may be modified by chamfering or cutting

- the facade may be made helical, or have other asymmetrical modifications - openings may also be added

Some of the early investigations into aerodynamic shape of buildings by Dutton and Isyumov [1] and Tamura, et. al [2] primarily looked at modifications like openings and corner cuts in a regular building, without altering the base shape. These alterations form an interesting basis for adding future dimensions to the present study. In fact, in cross comparisons in studies by Tanaka, Tamura et al. [3][4], Xie [5], etc. concludes that multiple modifications are superior to single modification in terms of aerodynamic efficiency.

However, with only one modification under consideration, alteration of the base polygon itself is considered to have the greatest impact: Hayashida and Iwasa [6] were the first to 
investigate this line of research. In selecting a base shape alternate to a square, an asymmetrical or symmetrical design may be opted for. However, since the study extends to seismic loads, asymmetrical shapes are more likely to fail, and hence symmetric polygons are investigated.

While a circular building offers the greatest symmetry, it is architecturally difficult to design a circular home, and with this in mind, a hexagonal shape is selected as the final modification: accounting for aerodynamic modification towards wind, symmetric structure for seismic resistance, and convenience of architectural design.

\subsection{Seismic effects}

The two different symmetrical structures, circular and square model, are compared on the basis of their response when subjected to constant acceleration by B. Samali, W. Jinwuth, K. Heathcote and C.Wang [9]. The circular plan structures resist greater forces as compared to square ones. This behaviour can be explained with the help of the concept center of rigidity and center of mass. In circular plan structures, center of mass as well as center of rigidity is the same. So the moment arm is zero and hence the torsion cause is zero. But in case of square shaped structures center of rigidity and center of mass are different, thus there is moment arm which causes torsion.

The Egyptian Codes of Practice are reviewed for wind and seismic loading by Khaled M. Heiza, Magdy A [8]. Tayel. This study shows that wind forces primarily depend on projected area and the intensity of wind. While the seismic forces depend on the zone factor, importance factor, plan of the building, soil coefficient and the weight of the building. The adequacy of the designed structure is checked on the basis of strength by comparing the effects of earthquake and wind forces on the buildings in Malaysia by Azlan Adnan, SuhanaSuradi [10]. In this study, three different comparisons are done between 1) static and dynamic analysis, 2) earthquake and wind forces and 3) linear and non-linear analysis.

A new theory, Earthquake Resistant Architecture, is proposed by Hugo Giuliani [14]. This theory helps the architects and structural engineers to avoid reduction in seismic resistant capacity of buildings when architectural and structural designs are blended together.

The present seismic zones in India are based on the data available till 1993 and from 2002 it is not updated. To overcome this, probabilistic seismic hazard assessment (PSHA) was carried by B. Ghosh, et.al [15] for some locations in Himalayan region and major cities in India.

The present study deals with assessing the influence of wind and earthquake on a symmetrical square and hexagonal plan configurations. Four metro cities of India were chosen for the present study to assess the best configuration that can sustain wind and earthquake.

\section{STRUCTURAL LAYOUT}

The architectural layout of the building was planned so that the structural layout could be decided accordingly. Equal floor area was used in both cases: $2500 \mathrm{~m}^{2}$. The final structural layout is outlined in Fig 1(a) and (b).

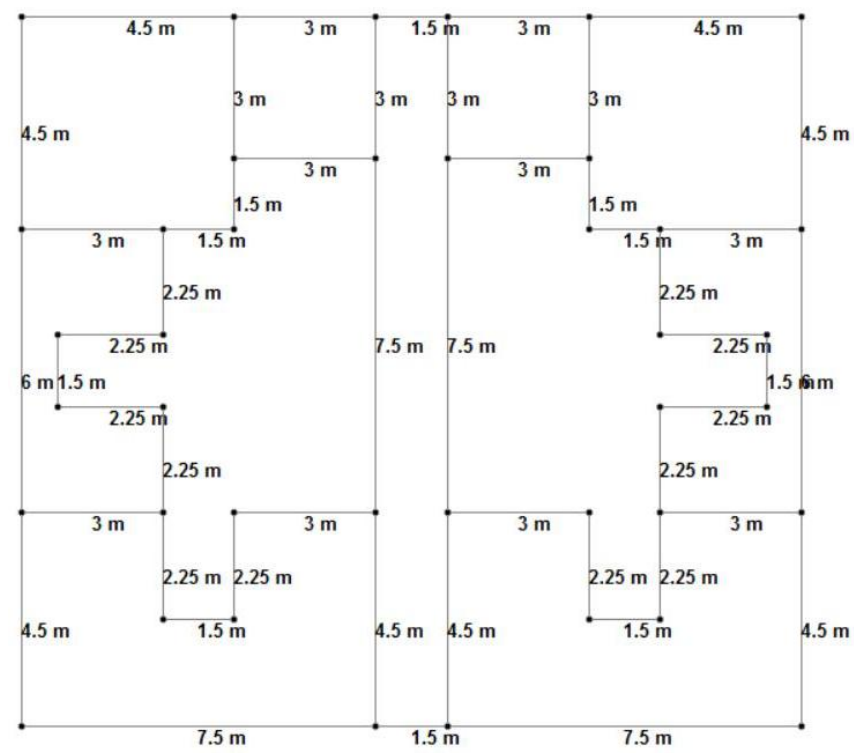

Fig 1 (a): Rectangular/square building - structural layout (top view)

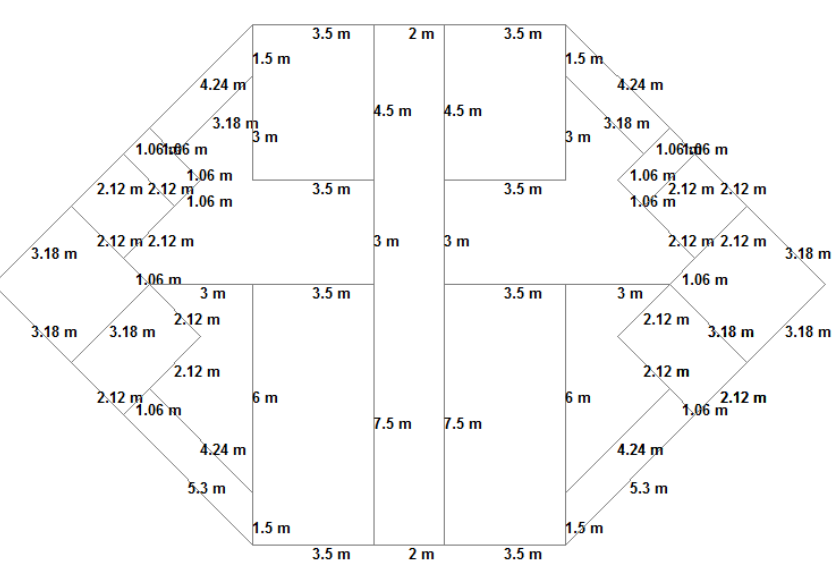

Fig 1 (b): Hexagonal building - structural layout (top view)

\section{MODELING IN STAAD}

The structural layout of beams and columns is modelled in STAAD.Pro V8i software. A primary level of analysis was run on four different types of models - hexagonal plan for wind, rectangular plan for wind, hexagonal plan for earthquake and rectangular plan for earthquake. Different load cases were applied according to conditions in the four different cities.

\section{Wind}

- No bracing or shear walls are provided in this analysis. As the altered base shape is the only modification, the effect is not expected to be very pronounced. 
- STAAD.Pro V8i accepts entry of floorwise wind intensity, as opposed to wind intensity on each individual member. This implies that wind intensity calculation was based on a blanket value for the whole floor, which does not factor the change in angle of attack of the wind due to hexagonal shape.

\section{Seismic}

- The hexagonal plan chosen is not a regular hexagon. Though it is symmetric about its both axes, it does not provide as much resistance to earthquakes as it would if it were a regular hexagon plan building. When comparison is done between a square and rectangular plan building, a square plan building will provide greater seismic resistance though both are symmetric about two axes. This is because center of rigidity and center of mass are closer in square plan than those in rectangular plan causing less torsion.

The generation of input load data for the model is explained in the section 3 .

\subsection{Dead Loads and Live Loads}

For the purpose of dead load calculations, M20 grade concrete is assumed to have been used, reinforced with $\mathrm{Fe}$ 415 grade steel. Load intensity of dead weight is an average of $3.5 \mathrm{kN} / \mathrm{m}^{2}$ and live load is assumed to have an intensity of $3 \mathrm{kN} / \mathrm{m}^{2}$.

\subsection{Load Combinations}

A large number of load combinations were entered for STAAD analysis. All of them are listed in Table 1. The same load combinations were applied across the parameters for the four different cities.

Table -1: Coefficients for various load combinations

\begin{tabular}{|c|c|c|c|c|}
\hline $\begin{array}{c}\text { Loading } \\
\text { No. }\end{array}$ & $\begin{array}{c}\text { Dead } \\
\text { Load } \\
\text { Coeff. }\end{array}$ & $\begin{array}{c}\text { Live } \\
\text { Load } \\
\text { Coeff. }\end{array}$ & $\begin{array}{c}\text { Wind } \\
\text { Load } \\
\text { Coeff. }\end{array}$ & $\begin{array}{c}\text { Seismic } \\
\text { Load } \\
\text { Coeff. }\end{array}$ \\
\hline
\end{tabular}

\begin{tabular}{|c|c|c|c|c|}
\hline Wind: & \multicolumn{5}{l|}{} \\
\hline 1 & - & - & 1 & - \\
\hline 2 & 1 & - & - & - \\
\hline 3 & - & 1 & - & - \\
\hline 4 & 1.5 & 1.5 & - & - \\
\hline 5 & 1.2 & 1.2 & 1.2 & - \\
\hline 6 & 1.5 & - & 1.5 & - \\
\hline 7 & 0.9 & - & 1.5 & - \\
\hline 8 & 1 & 1 & - & - \\
\hline 9 & 1 & 1 & 1 & - \\
\hline Seismic: & \multicolumn{5}{|l|}{} & & \\
\hline 1 & - & - & - & 1 \\
\hline 2 & 1 & - & - & - \\
\hline 3 & - & 1 & - & - \\
\hline 4 & 1.5 & 1.5 & - & - \\
\hline 5 & 1.2 & 1.2 & - & 1.2 \\
\hline 6 & 1.5 & - & - & 1.5 \\
\hline 7 & 0.9 & - & - & 1.5 \\
\hline 8 & 1 & 1 & - & - \\
\hline 9 & 1 & 1 & - & 1 \\
\hline
\end{tabular}

\subsection{Wind Load Calculation}

The calculation of wind loads is done in accordance with IS 875 (Part 3), with loads evaluated for each level of the building. This value is given by:

$$
p_{z}=0.6 V_{z}^{2}
$$

Here, $\mathrm{V}_{\mathrm{z}}$ is design wind speed. The following equation is used to evaluate design wind speed:

$$
V_{z}=V_{b} k_{1} k_{2} k_{3} k_{4}
$$

where,

$\mathrm{V}_{\mathrm{z}}=$ design wind speed at any height $\mathrm{z}$ in $\mathrm{m} / \mathrm{s}$,

$\mathrm{k}_{1}=$ probability factor (risk coefficient)

$\mathrm{k}_{2}=$ terrain roughness and height factor

$\mathrm{k}_{3}=$ topography factor

$\mathrm{k}_{4}=$ importance factor for the cyclonic region

The values of the basic wind speed as applicable to each city, are noted in Table 2 . Values of $\mathrm{k}_{1}, \mathrm{k}_{2}, \mathrm{k}_{3}, \mathrm{k}_{4}$ are calculated separately for each level and each city, in accordance with the standards [11]. Loads on floors below $10 \mathrm{~m}$ level are ignored in case of wind, as effect of wind load is not significant below that level.

Table -2:

\begin{tabular}{|c|l|c|c|c|}
\hline City & Chennai & Delhi & Kolkata & Mumbai \\
\hline $\mathrm{V}_{\mathrm{b}}$ & $50 \mathrm{~m} / \mathrm{s}$ & $47 \mathrm{~m} / \mathrm{s}$ & $50 \mathrm{~m} / \mathrm{s}$ & $44 \mathrm{~m} / \mathrm{s}$ \\
\hline
\end{tabular}

\subsection{Earthquake Load Calculation (Static Analysis)}

The calculation of seismic loads is done in accordance with the standards [12], with loads evaluated for each level of the building. This value is given by:

$$
\text { Design base shear } V_{b}=A_{h} W
$$

The design horizontal seismic coefficient $A_{h}$ for a structure:

where,

$$
A_{h}=\frac{Z I}{2 R} \frac{S_{a}}{g}
$$

\footnotetext{
$\mathrm{Z}=$ zone factor,

$\mathrm{I}=$ Importance factor ( $\mathrm{I}=1$ for residential building)

$\mathrm{R}=$ Response reduction factor $(\mathrm{R}=5$ as building is provided with moment resisting frames)
}

$\mathrm{S} / \mathrm{g}$ factor is calculated based on the natural period of the structure in that direction

The fundamental natural period $\mathrm{T}$ for a structure:

$$
T=\frac{0.09 h}{\sqrt{d}}
$$

where, $\mathrm{h}=$ height of the building

$\mathrm{d}=$ width of the building in that direction 
Table -3. Seismic zones for cities:

\begin{tabular}{|c|c|c|c|c|}
\hline City & Chennai & Delhi & Kolkata & Mumbai \\
\hline Zone & II & IV & III & III \\
\hline Zone Factor Z & 0.10 & 0.16 & 0.24 & 0.36 \\
\hline
\end{tabular}

\section{RESULTS AND ANALYSIS}

Results are mainly measured in terms of story drift and maximum deflection across the cities, for both $\mathrm{X}$ and $\mathrm{Z}$ directions and for both configurations of buildings. The graphical correlations are given in Charts $1-5$ below, followed by observations.

\section{Story Drift}

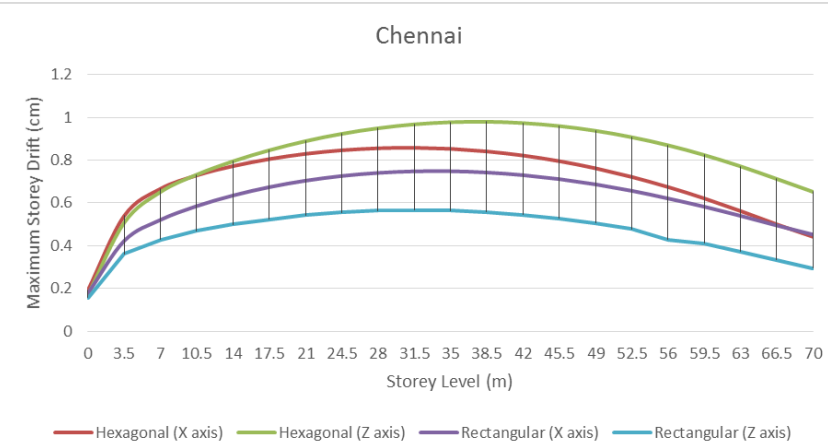

1 (a)

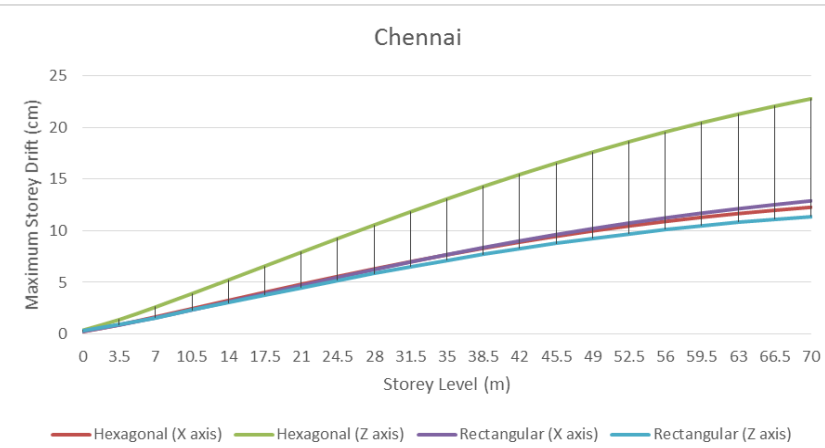

1 (b)

Chart 1: Story drift in Chennai under - (a) seismic and (b) wind loading

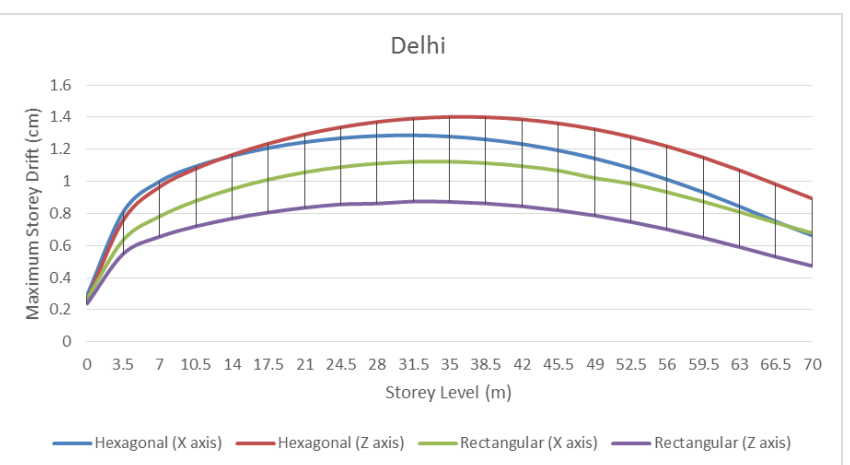

2 (a)

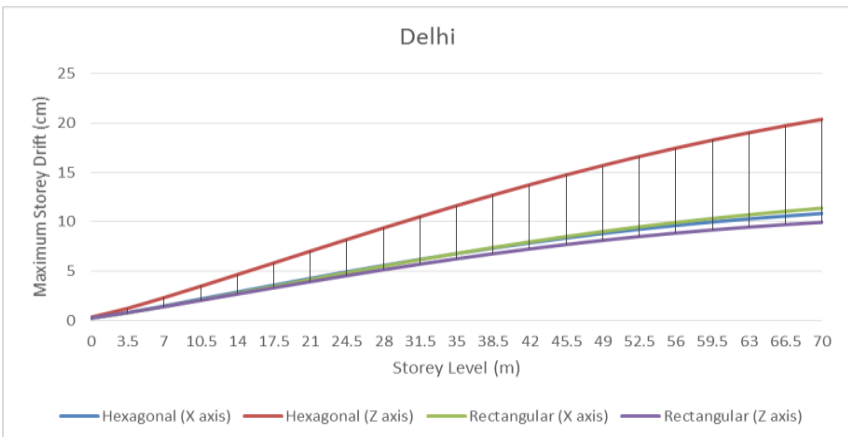

2 (b)

Chart 2: Story drift in Delhi under - (a) seismic and (b) wind loading

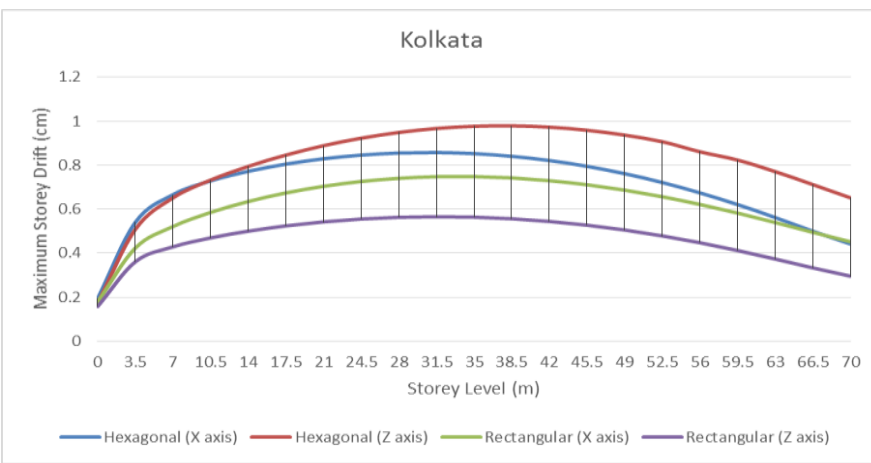

3 (a)

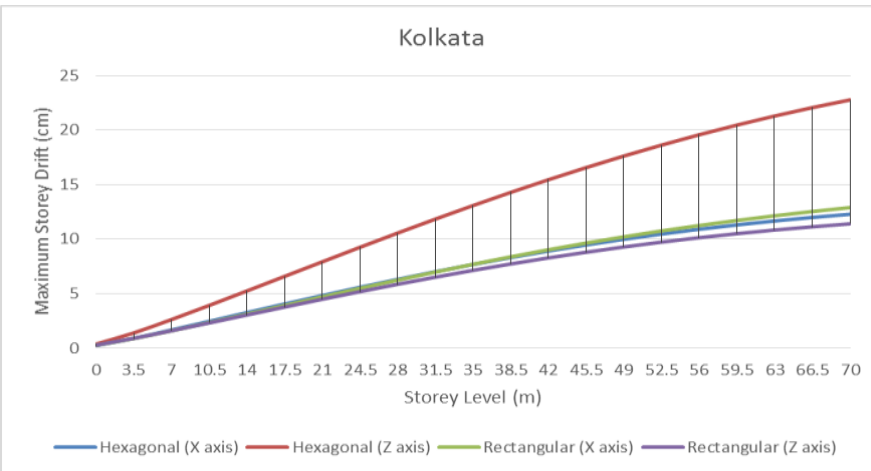

3 (b)

Chart 3: Story drift in Kolkata under - (a) seismic and (b) wind loading

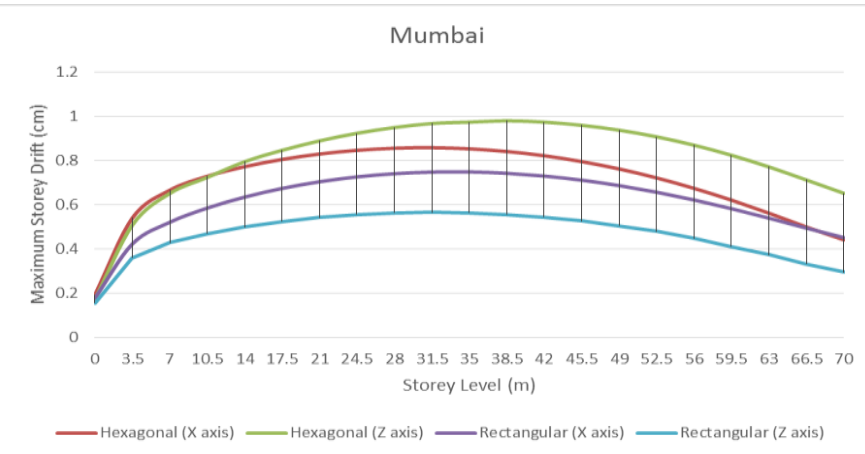

4 (a) 


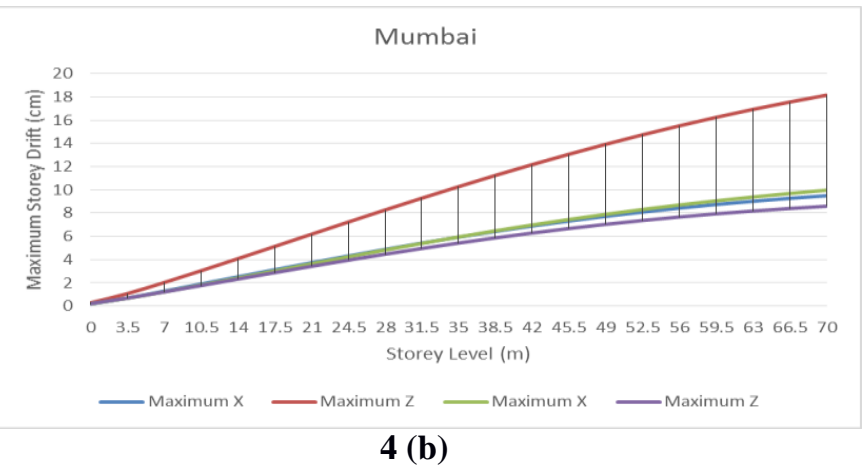

Chart 4: Story drift in Mumbai under - (a) seismic and (b) wind loading

Story drift under seismic load is generally observed to increase initially till about mid-point of the building, reach a maximum, and then decrease thereafter. The maximum drift uniformly occurs between level of $31.5 \mathrm{~m}$ and $38.5 \mathrm{~m}$ in each case ( $35 \mathrm{~m}$ being the midpoint). The hexagonal shape generally shows a higher maximum along $\mathrm{Z}$ direction and the rectangular, along $X$ direction. The increase from minimum to maximum is about 3-3.5 times in $\mathrm{X}$ direction and varies between 2.5-4.5 times in the $\mathrm{Z}$ direction. Hexagonal building in Delhi shows maximum story drift of $1.4012 \mathrm{~cm}$ (along Z), and rectangular building in Kolkata shows the minimum, at $0.1575 \mathrm{~cm}$ (along Z). Hexagonal building in Chennai shows the highest increase along both $X$ and $\mathrm{Z}$ directions - at 3.5 and 4.5 times, respectively.

Story drift under wind load is generally seen to increase consistently, varying between $0.1884 \mathrm{~cm}$ (X direction of hexagonal building in Mumbai) and $22.7697 \mathrm{~cm}$ ( $Z$ direction of hexagonal building in Chennai).Maximum and minimum uniformly occur at the top and bottom storys, respectively. The rise from minimum to maximum is comparable for both types of buildings along $X$ direction: with a 47-50 times increase. Along $\mathrm{Z}$ direction, rectangular buildings show a lower variation (about 40 times), while hexagonal buildings show the largest variation overall, at 60-62 times increase. Hexagonal building in Mumbai shows the highest increase: with the maximum over 62 times the minimum.

Overall, wind loads cause larger minimum, maximum, as well as percentage variation in every case of story drift. The maximum drift due to wind is around 15 times more than that due to earthquake. Chennai shows the largest variation in most cases. Delhi shows the largest drift under seismic load, while Chennai and Kolkata show largest drift under wind load.

\section{Maximum Deflection}

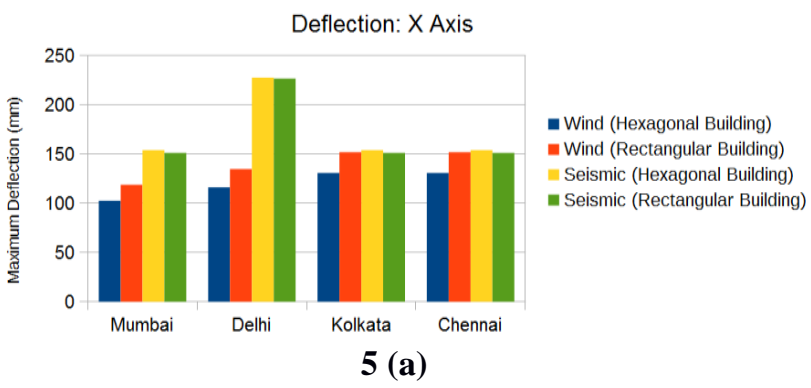

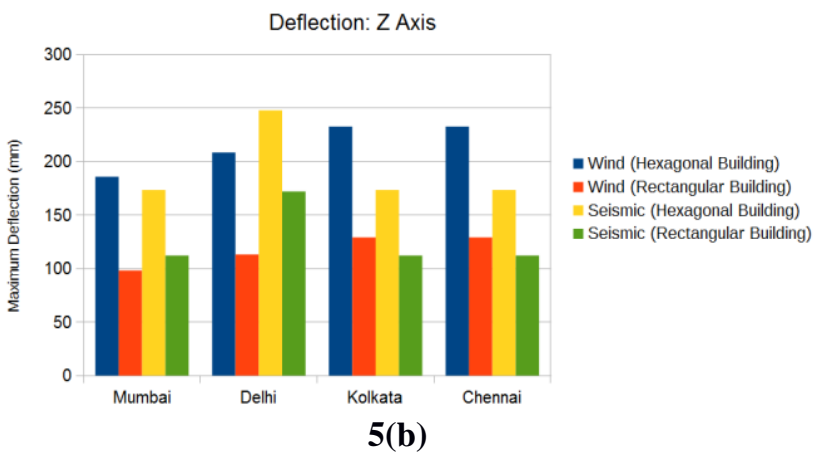

Chart 5: Maximum deflection along - (a) X direction and (b) $\mathrm{Z}$ direction

Maximum deflection due to seismic loads (both hexagonal and rectangular) is found to be the same for all cities except Delhi - which shows a $40-50 \%$ increase over the values in the other cities. Difference between hexagonal and rectangular buildings along $\mathrm{X}$ direction is negligible (slightly higher for hexagonal), but along the $\mathrm{Z}$ direction, hexagonal buildings show about $50 \%$ greater deflection. This trend is uniform across all cities.

Maximum deflection due to wind loads is the same for Kolkata and Chennai - these cities also display the highest such deflection. Mumbai shows the least maximum deflection - about 25-30\% lower than Chennai/Kolkata in each case. However, comparison between hexagonal and rectangular buildings long $\mathrm{Z}$ direction shows a reverse trend - variation between the two is highest at Mumbai, at about a $90 \%$ increase (for hexagonal) and an $80 \%$ increase in Kolkata/Chennai (also for hexagonal). Difference along X direction is considerably lower, with only about a $16 \%$ difference.

\section{Modal Analysis}

The frequency and time period corresponding to two different configurations (hexagonal and rectangular) subjected to wind and earthquake are shown in Table 4.

Table 4: Mode Shapes

\begin{tabular}{|c|c|c|c|c|}
\hline \multirow{2}{*}{ Mode } & \multicolumn{2}{|c|}{ Hexagonal } & \multicolumn{2}{c|}{ Rectangular } \\
\cline { 2 - 5 } & $\begin{array}{c}\text { Frequency } \\
(\mathrm{Hz})\end{array}$ & $\begin{array}{c}\text { Time } \\
\text { Period (s) }\end{array}$ & $\begin{array}{c}\text { Frequency } \\
(\mathrm{Hz})\end{array}$ & $\begin{array}{c}\text { Time } \\
\text { Period (s) }\end{array}$ \\
\hline $\mathbf{1}$ & 4.401 & 0.227 & 4.673 & 0.214 \\
\hline $\mathbf{2}$ & 4.722 & 0.212 & 4.952 & 0.202 \\
\hline $\mathbf{3}$ & 4.875 & 0.205 & 5.136 & 0.195 \\
\hline $\mathbf{4}$ & 5.753 & 0.174 & 6.097 & 0.164 \\
\hline $\mathbf{5}$ & 6.21 & 0.161 & 6.223 & 0.161 \\
\hline $\mathbf{6}$ & 6.775 & 0.148 & 6.961 & 0.144 \\
\hline
\end{tabular}




\section{CONCLUSIONS}

The present study is preliminary in nature and further work is required before arriving at any optimal construction solutions for the metro cities of India. However, based on the analysis carried out the following preliminary conclusions can be listed as below:

- Delhi displays the highest vulnerability to earthquake, while other cities are moderately affected.

- Effect of wind is most pronounced in Chennai and Kolkata.

- Mumbai is relatively less affected by wind, despite being a coastal location.

- The modification to hexagonal base shape - with no other alteration - does not have any real impact where the structural skeleton is considered. It is possible that multiple modifications, or addition of bracings, will give a better result against wind loads.

- The altering of base shape from square to hexagonal does not help seismic resistance, and therefore other options should be explored for seismic resistance. Such resistance is especially necessary for constructions in Delhi.

\section{REFERENCES}

[1]. R. Dutton and N. Isyumov. "Reduction of tall building motion by aerodynamic treatments"

[2]. Kolchi Miyashita, JunjiKatagiri, Osamu Nakamura, Takeshi Ohkuma, Yukio Tamura, Masaru Itoh and TadashlMimachi."Wind-induced Response of High Rise Buildings: Effects of Corner Cuts or Openings in Square Buildings"

[3].Hideyuki Tanaka, Yukio Tamura, Kazuo Ohtake, Masayoshi Nakai, Yong Chul Kim. "Experimental investigation of aerodynamic forces and wind pressures acting on tall buildings with various unconventional configurations"

[4]. Yong Chul Kim, Yukio Tamura, and Sangdae Kim."Wind Load Combinations of Atypical Supertall Buildings"

[5].JimingXie. "Aerodynamic optimization of super-tall buildings and its effectiveness assessment."

[6].H. Hayashida and Y. Iwasa."Aerodynamic Shape Effects of Tall Buildings for Vortex Induced Vibration"

[7]. Prem Krishna."Wind Loads on Low Rise Buildings - a review"

[8]. Khaled M. Heiza and Magdy A. Tayel."Comparative Study of The Effects of Wind and Earthquake Loads on High-rise Buildings"

[9] B. Samalia, W. Jinwuth, K. Heathcote and C. Wang

"Seismic Capacity Comparison between Square and

Circular Plan Adobe Construction"

[10] Azlan Adnan, SuhanaSuradi“"Comparison on the Effect of Earthquake and Wind loads on the Performance of Reinforced Concrete Buildings"

[11] IS 875: Part (3) - Wind Loads on Buildings and Structures.
[12] IS 1893 Part (1) - Criteria for Earthquake Resistant Design of Structures.

[13] IS 456 (2000) - Plain and Reinforced Concrete.

[14] Hugo Giuliani."Seismic Resistant Architecture: A Theory For The Architectural Design Of Buildings In Seismic Zones"

[15] B. Ghosh, J.W. Pappin\& M.M.L. So, K.M.O. Hicyilmaz"Seismic Hazard Assessment in India”

\section{BIOGRAPHIES}

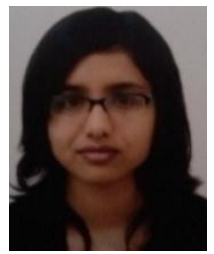

Undergraduate student in the Civil Engineering Department of BITS Pilani (Hyderabad Campus), currently in final year of study. Interests: Wind engineering and sustainability.

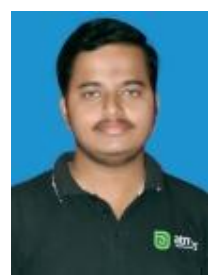

Undergraduate student in the Civil Engineering Department of BITS Pilani (Hyderabad Campus), currently in final year of study. Interests: Earthquake Resistant Design of Structures

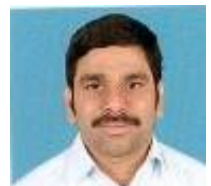

Author is a Lecturer, Department of Civil Engineering, BITS Pilani-Hyderabad Campus. Fields of interest are behavior of high rise structures subjected to wind and earthquake, Fracture Mechanics of Concrete Structures, Numerical modeling of concrete structures using FEM 